\title{
Second Trimester Antepartum Hemorrhage
}

National Cancer Institute

\section{Source}

National Cancer Institute. Second Trimester Antepartum Hemorrhage. NCI Thesaurus.

Code C125493.

Excessive blood loss within the second trimester but prior to onset of labor. 